\title{
Manuscript Collections, Archives, and Special Collections: Their Relationships
}

\section{Richard C. Berner}

Manuscript collections have evolved into sizable collections that must be handled more effectively if they are to be integrated fully with other relevant materials. There are two main reasons for this. First, manuscripts have been treated as discrete items representing the accidental documentary remains of the past and have become dissociated from related items. As discrete items their status as rarities may be enhanced, but this has discouraged the creation of comprehensive controlled information sources. Second, since twentieth century materials now constitute the bulk of most major manuscript collections, the traditional "rarities" approach is no longer satisfactory. An examination of the public archives tradition provides some answers as to how manuscript might be treated. However, few directors of special collections departments are likely to adopt processing and intellectual controlled programs that originated from the public archives tradition. Thus, manuscript collections will continue to lag in their development and will be less accessible to users as a result.

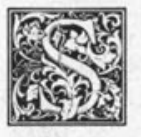

pecial collections units were formed for administrative convenience in libraries to take care of miscellaneous nonconforming library materials such as photographic collections, incunabula, and historical and literary manuscripts; " archives" of the institutional variety are a more recent addition to the list. Traditionally these materials have been administered by existing techniques and practices of librarianship because more suitable practices either had not been developed to handle them, or practices were underdeveloped, or suitable practices that had been developed were considered irrelevant.

Many of these "odds and ends" have become sizable collections. This is particularly true of manuscript and institutional archival records. The scale of such collections demands that they be treated on their own terms, both intellectually and administratively; otherwise they cannot both be treated adequately and integrated fully with all other relevant materials. ${ }^{1} \mathrm{~A}$ look at the historical development of special document collections shows why this is so.

First, let us turn to historical manuscripts. Normally, such materials were acquired opportunistically and were not the conscious product of a coherent collection development policy. Private collectors sold or donated their collections to libraries or historical societies, and these collections served as a nucleus for future institutional collecting.

What these manuscripts also represent are the accidental documentary remains of the past, collected then made publicly accessible in libraries and historical societies. The items and clusters of items that

Richard C. Berner has recently retired as head of the University Archives \& Manuscripts Division, University of Washington Libraries, Seattle, Washington 98195. This paper was presented at the Rare Books and Manuscripts Section general program meeting at the 1983 ALA Annual Conference in Los Angeles. 
were accessioned had become dissociated from related items with which they were once joined in series. They were considered not only "rare" but prestigious to own.

The combination of being rare and separated from related items with which these materials were formerly linked suggested that they be treated like books. And, since there is only one body of knowledge to deal with books-librarianship-this is the way they were treated, as discrete items.

Item catalogs, special subject indexes, shelf lists, and other finding aids gave provisional access prior to calendaring. Given the accidental nature of the materials, these techniques sufficed until collecting of twentieth century materials began in earnest in the 1930s. By the mid-1950s these twentieth century materials constituted the bulk of most major manuscript collections.

The "register" was added by the Library of Congress in the 1950s to the above array of finding aids. ${ }^{2}$ In combination, these aids represent what I characterize as one of the chief elements of the Historical Manuscripts Tradition. Each finding aid was the coequal of the other because there was no single point from which the information in them could be approached as in a union catalog. This system persists although it has been rendered obsolete by Chapter 4, Manuscript Collections, of the AACR2. ${ }^{3}$

With this historical backdrop in mind, let us turn to another line of development, that of the Public Archives Tradition (PAT). From the start it was agreed that library practices were inapplicable, and that governmental agency records should be kept according to their origins instead of being distributed among preconceived subject and form classes.

Collections of twentieth century materials share all of the essential characteristics of public archives due to their integral or organic character. In the PAT, record items derive their meaning from their original association with other items in the same and related record series. To deal with massive twentieth century collections effectively, methods for intellectual control were borrowed from the PAT.
A further complication, in academic libraries at least, is that administratively these historical manuscript collections remained in special collections units even after the collections had developed beyond the embryo stage. Often there is more than one category of manuscript collection at a single institution. Collections are usually autonomous, even to the degree that there may be no union catalog of all the manuscript collections at that institution-an ironical by-product of the Historical Manuscripts Tradition. Further, it is in the nature of special collections units that each component tends to be independent on the basis of format, but, nevertheless, initially each is treated technically as though existing techniques of librarianship could provide suitable access. Inevitably, disillusionment follows and either alteration of library techniques occurs or collections are abandoned altogether.

Recently, college and university archives have been added to academic library collections. They constitute the largest growth sector in the archival field since the mid-1960s. Usually, these also are administered separately but under a special collections director whose background is in rare books or premodern manuscripts. The main problem is to link the parts together by developing appropriate methods of intellectual control and access. But collecting itself must be guided by coherent policy if there is to be a foundation on which linkages can be structured. ${ }^{4}$

Institutional archival programs try to achieve authoritativeness by means of record management techniques that were developed originally in the National Archives to control the life cycle of records. Collecting efforts for manuscript collections of all types have not benefited from this records management perspective. The one exception is at those institutions with standing archival agreements with private corporate bodies and individuals which guarantee the transfer of inactive records and papers on a regular basis to the manuscript collection. This trend is growing and is realistic if our objective is to maintain the integrity of the documentation. In such cases, the manuscript collection staff serves as records manager for 
the person or corporate body whose records are transferred to custody of the manuscript repository.

In addition to serial continuity, collecting must aim at comprehensiveness. No one issue is adequately documented from the records of only one single participant if there is more than one party to an issue. If comprehensiveness is to be a major factor in collection development, the collector must acquire related sources or know related sources at other repositories.

To attain their common goal, repositories which have authoritativeness as an objective must cooperate. Indeed, since the late 1960 s cooperation has been gradually displacing competitiveness. But cooperation needs to be in concert so that the growing network of archival sources will become rationalized deliberately.

A similar transition must take place in the orientation of directors of special collections units if the records and papers of contemporary society are to be collected and administered successfully. The directors of such collections typically came from rare books backgrounds and they have carried over that orientation to manuscript collecting and administration; they must adapt to changed needs and environments. Authoritativeness and comprehensive coverage as goals conflict with the rarities approach to collection building.

Records appraisal also poses a nagging problem. Mass must be reduced to manageable proportions for the benefit of the repository and the user alike. With twentieth century materials now constituting the major portion of the typical manuscript collection, the motive for collecting has changed to that of seeking a fullness of documentation that makes possible authoritative research.

Essentially, appraisal is a records management function. It is accomplished mainly by means of records disposition and retention schedules, which are the first formal appraisal documents. There is now general agreement that records management should be the foundation for any institution's own archive. It follows that a manuscript repository also must perform these records management tasks on the twentieth century papers and records it collects. This records management direction takes the program even further out of the Historical Manuscripts Tradition and calls into question the appropriateness of its place under a special collections administrator.

Thus far, two dynamic factors have been identified that help to distinguish manuscript collections and institutional archives from other materials that fall under library administration. These are collection development and intellectual control, with control responding to the collecting. Together, they constitute a dynamic equilibrium, unconscious though it may bemethods of control have changed as the nature of collecting has changed.

Scale is a major factor to consider. If the aim is comprehensive coverage and continuity of major record series, then programs must be developed to achieve these objectives as efficiently as possible. Storage space, processing procedures, finding-aid systems, and informationsharing are important considerations in the implementation of necessary programs. Also, records management must become an integral element of the program. One wonders if the traditional special collections division is appropriate to administer such collections in addition to its other components of far lesser scale and complexity.

Scale also affects the methods of control that are chosen. Processing and intellectual control programs must abandon those practices that are rooted in the Historical Manuscripts Tradition and instead fully incorporate procedures of the Public Archives Tradition. This means abolition of traditional cataloging with its randomness and, instead, articulating arrangement and description as two parts of a single control process, and a control document must be produced from the indexing. The inventory format is the only format devised thus far that is suitable for use as a control document. Indexing from it can be under control at all times. That a controlled information source for cataloging is a novel idea is its own commentary on the state of the art.

This radical departure is one that few di- 
rectors of special collections units are prepared to take emotionally and intellectually. And, if they choose this radical departure in order to cope with twentieth century collections, will they still be able to justify administering these collections as part of a special collections unit, or for that matter, other comparable special materials collections that have reached maturity? The incongruity seems blatant. Little is lost to a special collections unit by allowing manuscript collections and institutional archives to become autonomous; to be administered in terms of their own characteristics. Both scale and technical considerations seem to justify autonomy.

Modern manuscript collections and institutional archives are no longer infantile, but are vigorous progeny requiring that they be treated on their own terms.

\section{REFERENCES AND NOTES}

1. The historical background can be read in Richard C. Berner, Archival Theory and Practice in the United States: A Historical Analysis (Seattle: Univ. of Washington, 1983).

2. The register was adapted by the Library of Congress from the preliminary inventory format employed by the National Archives, and was inspired by Solon J. Buck when he became head of the Manuscripts Division upon resigning as archivist of the United States in 1948. The register is divided into several sections, the main ones being a scope and contents note, biographical outline, serials listing, and a container list. The scope of contents note provides the only source for added entries, while the container list would be the richest source if used for that purpose. See passim, Chapter 3, and Katherine Brand, "Development in the Handling of Recent Manuscripts in the Library of Congress," American Archivist 16:99-104 (Apr. 1953); and "The Place of the Register in the Manuscripts Division of the Library of Congress," American Archivist 18:59-67 (Jan. 1955).

3. See Berner, passim, Chapter 6. AACR2 Chapter 4 on manuscript collections recommends that cataloging be done from the "whole collection," which means that it be done from the actual manuscripts, and not from a secondary source such as one or more finding aids. To correct for this impractical recommendation, a task force draft report generated by the Manuscripts Division of the Library of Congress has recommended that finding aids be used as the principle source of cataloging information. Lacking here is any idea that there should be a controlled information source.

4. For some of the most challenging thought on this problem see F. Gerald Ham, "The Archival Edge," American Archivist 38:5-13 (Jan. 1975); and "Archival Strategies for the Post-Custodial Era," American Archivist 44:207-16 (Summer 1981).

5. Although there is voluminous literature on records management, a useful introduction may be found in Wilmer Maedke, Mary Robek, and Gerald Brown, Information and Records Management (New York: Glencoe, 1974), p.1-38. 